Çukurova Üniversitesi Mühendislik Mimarlık Fakültesi Dergisi, 31(2), ss. 421-435, Aralık 2016

\title{
Rins Yıkamanın Denim Kumaş Performansı Üzerindeki Etkilerinin Araştırılması
}

\author{
R. Tuğrul OĞULATA ${ }^{* 1}$, Ahmet NERGís ${ }^{1}$ \\ ${ }^{1}$ Çukurova Üniversitesi, Mühendislik Mimarlık Fakültesi, Tekstil Mühendisliği Bölümü, Adana
}

Geliş tarihi: 10.06.2016 Kabul tarihi: 23.11.2016

\section{$\ddot{\mathbf{O z}}$}

Rins yıkama, denim kumaşlarda en sık kullanılan yıkama uygulamalarından biridir. Bu çalışmada, rins yıkamanın, denim kumaş özellikleri üzerindeki etkileri incelenmiştir. Seçilen bir denim kumaşa, rins yıkama esnasında farklı sıcaklık ve süre seviyelerinde yıkama denemeleri yapılmışıtır. Yapılan araştırmada, yıkamaların kumaşlar üzerindeki etkisini incelemek amacıyla, tekstil kumaşlarının performans tayininde kullanılan test metotları uygulanarak elde edilen sonuçlar istatistiksel metotlarla analiz edilmiştir. Deneysel çalışma sonuçlarının değerlendirilmesi ile; rins yıkama prosesinde yıkama süresinin gramaj, en, sertlik, çözgü uzama, dönme, atkı kopma ve çözgü kopma sonuçları üzerinde etkili iken, sıcaklığın ise sadece atkı ve çözgü kopma mukavemet sonuçları üzerinde etkili olduğu görülmüştür.

Anahtar Kelimeler: Denim, Rins yıkama, Mukavemet, Katılık, Gramaj

\section{Investigation of Effects of Rince Washing on Performance for Denim Fabrics}

\begin{abstract}
Rince wash is one of the most common washing application method on denim fabrics. In this study, the effects of the rince wash on denim fabrics has been researched. During rince wash processes, with different tempature and duration levels, some washing trials have been applied to a selected denim fabric. For the aim of investigation of the washing effects on denim fabrics, the obtained test results, by using the test methods which are performed for determination the performance of textile fabrics, have been analysed with statistics methods in this study. After the evaluation of experimental work results, it has been observed that the washing duration is very effective on weight, width, stiffness, warp elongation, movement, weft and warp tensile strength, while the temperature results were only shown to be effective on the warp and weft tensile strength results.
\end{abstract}

Keywords: Denim, Rince wash, Strength, Stiffness, Weight

\footnotetext{
*Sorumlu yazar (Corresponding author): R. Tuğrul OĞULATA, ogulata@cu.edu.tr
} 


\section{GíRiş}

Günümüzde, denim kumaştan yapılan giyim eşyaları, her yaştan ve her kesimden insanın “'yüksek moda ürünü giysiler”, olarak algıladığ tekstil ve konfeksiyon mamulleridir. Ortaya çıktığ 19. Y.Y.'dan beri devamlı gelişme kaydeden ve moda yaratımında lider akımlardan olan denim kumaşlar, şu anda modanın vazgeçilmez bir parçasıdır. Ünlü moda markaları, değişik ve şaşırtıcı bir koleksiyon yapmak istediklerinde denim kumaşı tercih etmektedirler. Bunun asıl nedeni, genç kitlelerin denim ürünlere olan talebinin artırılması ve bu sayede, değişen yaşam tarzlarının denim ürünlere uygulanarak yeni moda eğilimlerinin yaratılmasıdır. Yaratılan yeni moda akımları, müşterilerin denim ürünlere daha fazla yönelimini sağlamakta ve üretici firmaların yıllık cirolarında önemli ölçüde artışlar sağlamaktadır [1].

Denim kumaş ürünleri için önemli işlemlerden biri yıkama operasyonudur. Dikilmiş denim giysinin, özel yıkama makinelerinde belirli reçete ve tekniklere göre yıkanarak üzerinde bulunan haşılların sökülmesi, değişik renk ve tuşe kazandırılması işlemidir. Jeans yıkama teknolojisi tüketici istekleri ve modanın etkisi ile yeni renk tonları ve efektler yaratma amacına yönelmiştir. Blue jeans'in temel özelliği, yıkandıkça rengi açılan indigo boyar madde ile boyanmış olmasıdır [2]. Rins yıkama, denim kumaşlarda kullanılan yıkama uygulamaları içinde en sade olanıdır. Kumaş kısa bir süre suda durulama işlemine tabi tutularak mümkün olduğu kadar az efekt verilir. Genelde kuru ve parlak görünümün elde edilmek istenen durumlarda uygulanır. İngilizcede "rince" ya da "one wash" olarak geçen bu yıkama çeşidinde, ürünler soğuk ya da 1lık suda, kısa ya da orta süreli olarak yıkanırlar.

Rins yıkama hafif bir yıkama prosesi olması nedeniyle kumaşların fiziksel özellikleri üzerinde çok büyük değişimlere neden olmamakla birlikte, en yaygın kullanılan yıkama proseslerinden biri olması ve kumaştaki yıkama sonrası en küçük değişimlerin bile dikilmiş ürün üzerinde büyük sonuçlar doğurması nedeniyle dikkatle incelenmesi ve iyi analiz edilmesi gereken bir proses olduğu şüphesizdir. Burada önemli bir konu ise, genel olarak literatürde yer alan çalışmaların büyük bir çoğunda, rins yıkama ile diğer yıkama türleri arasındaki farklılıklar incelenmiştir. $\mathrm{Bu}$ nedenle tek başına rins yıkama prosesi içindeki değişimlerin incelenmesi ve bunun istatistiksel olarak geniş bir perspektifte değerlendirilmesi, etkili faktörlerin ortaya çıkarılması önem arz etmektedir. Özellikle kumaş üzerinde yapılan en önemli ve dikilmiş üründe en fazla etki edebileceği düşünülen fiziksel testlerin büyük bir çoğunu ortaya koyarak kumaşta yıkama sonrası ortaya çıkan değişimlerin tespit edilmesi ve bir bütün olarak ilişkilerin istatistiksel olarak incelenmesi amacıyla deneysel çalışmalar yapılmıştır. Yapılan çalışmalarda rins yıkama prosesindeki en etkin parametreler olan yıkama sicaklığı ve süre faktörlerinin belirli seviyelerde değişimlerle, kumaş performans sonuçları üzerindeki etkileri araştırılmıştır. Bu değişimlerin kumaştaki etkileri incelenmiş, önemli çıkarımlar elde edilmiştir.

\section{2. ÖNCEKİ ÇALIŞMALAR}

Literatürde denim yıkama işlemiyle ilgili yapılan çalışmalardan bazıları bu bölümde özetlenmiştir. Card, Moore ve Ankeny [3], jean hazır giyim ürünlerinde yıkama işlemlerinin fiziksel özelliklere etkisini araştırmıştır. \%100 pamuk denim kumaştan hazırlanan jeanlere enzim ve taş yıkama işlemleri uygulanmış, yıkama öncesi ve yıkamalar sonrasındaki boncuklanma ve aşınma dayanımları incelenmiştir. Yıkama öncesinde bulunan boncuklanma ve aşınma oranlarının, enzim ve taş yıkama sonrası bulunan oranlara göre daha fazla olduğu görülmüştür. Aslan ve Körlü [4] tarafindan yapılan çalışmada, haşıl sökme işlemi uygulanmış ve uygulanmamış çeşitli denim kumaş tipleri üzerinde farklı koşullarda uygulanan enzim ile yıkama işlemlerinin neden olduğu değişimler boyut, sıklık, renk ve ağırlık değişimleri, geri boyama, yırtılma dayanımı gibi parametreler açısından incelemiştir. Deneysel çalışmaların sonucunda, denim kumaşlara enzimatik yıkama işlemi öncesinde haşıl sökme uygulamasının, söz konusu parametreler üzerinde etkili olduğu bulunmuştur Khedher, Dhouib, Msahli ve Saklı [5], endüstriyel bitim işlemlerinin denim kumaşların mekanik özellikleri üzerindeki etkilerini araştırmışlardır. 
Çalışmada orta ve ağır gramajlarda 4 farklı denim kumaş kullanılmıştır. 4 farklı yıkama (rins, enzim, taş, enzimli taş) ve 5 farklı özel uygulama (firçalama, zımpara, reçine, ağartma, permanganat sprey ile yumuşatma) üzerinden kombin çalışmalar yapılmıştır. İşlemler sonrasında denim kumaşın yırtılma mukavemeti ve kopma mukavemeti testleri yapılıp yıkama öncesi ile karşılaştırılmıştır. Çalışmalar sonucunda, yıkama işlemlerinin kumaşın mekanik özelliklerini olumsuz etkilediği görülmüş istatistiksel olarak da aynı sonuç elde edilmiştir. Yi [6], çalışmasında, enzim yıkama, enzimli ağartma, enzimli taş yıkama ve enzimli taş ve ağartma gibi yıkama proseslerinde optimum yıkama efektinin yakalanması amacıyla farklı yıkama sürelerinde yıkamalar yapılmıştır. Çalışmada \%100 pamuk ve \%99 pamuk \%1 elastan olmak üzere iki farklı kompozisyonda denim kumaş kullanılarak elde edilen yıkamaların kumaş kopma mukavemeti ve elastikiyet değerleri üzerine etkileri incelemiştir. Bağıran [1], çalışmasında, denim ürünlere son görüntüsünü kazandıran yıkama işlemlerinin ayrıntılı incelemesini yapılmıştır. Yıkama işlemleri öncesinde ortaya çıkabilecek sorunlara karşı önlemlerin alınması ile bu işlemler sırasında ortaya çıkabilen sorunlara çözümler bulunması amacıyla incelemelerde bulunulmuştur. Yapılan farklı yıkamalar ve işlemler sonrasında kumaş renk ve mukavemet performanslarının değişimleri incelenmiştir. Khan, Mondal ve Uddin [7], denim ürünlerde yapılan ağartma yıkamasında kullanılan ağartıcı miktarı, sıcaklık ve süre gibi parametrelerin kumaş kopma mukavemeti, stiffness, elastikiyet, gramaj, renk kirletme, nem alma gibi özelliklerini ne yönde etkilediğini incelenmişlerdir. Yapılan çalışmada, kopma mukavemeti, stiffness, gramaj ve renk gibi değerlerde azalma görülmüştür. Ağartma işlemi uygulanmış kumaşın mikroskopla yapılan inceleme neticesinde yüzeyinde daha fazla çatlama ve ayrışma tespit edilirken, iplik bünyesinde bulunan liflerin ağartma sonrasında azalması sonucunda, yüzeyin daha pürüzlü ve zayıf görüntüye sahip olduğu görülmüştür. Yıkanmamış kumaşın ise daha pürüzsüz, düz bir görüntüye sahip olup, yüzeyin daha sert ve su emiciliğinin ağartılmış kumaşa göre daha az olduğu tespit edilmiştir.

\section{MATERYAL VE METOT}

\subsection{Materyal}

Yapılan yıkamalarda en çok üretilen temel tiplere örnek olması amaciyla gramaj olarak özellikle 10$12 \mathrm{oz} / \mathrm{yd}^{2}$ aralığında olan bir kumaş tipi seçilmiştir $\left(1 \mathrm{oz} / \mathrm{yd}^{2}=33,91 \mathrm{gr} / \mathrm{m}^{2}\right)$. Bu gramaj aralığında bulunan kumaşlar, denim piyasasında her türlü yıkama ve kullanıma uygun olup,. dayanım, konfor ve konstrüksiyon özelliklerine baktığımızda da yaygın olarak kullanılan \%98 pamuk $\% 2$ elastan elyaf içeriğine ve $3 / 1 \mathrm{Z}$ dimi konstrüksiyona sahiptir. Ayrıca her türlü yıkama işlemine dayanabilecek mukavemete sahip olması nedeniyle de giysi tasarımında farklı yıkamaların kullanılmasına da imkan vermektedir. Çalışma yapılan kumaşın genel özellikleri Çizelge 1'de yer almaktadır.

Çizelge 1. Numune iplik ve kumaş özellikleri

\begin{tabular}{|l|l|}
\hline Örgü & $3 / 1 \mathrm{Z}$ Dimi \\
\hline Hammadde & \%98 Pamuk \%2 Elastan \\
\hline Gramaj & $11,2 \mathrm{oz} / \mathrm{yd}^{2}\left(380 \mathrm{gr} / \mathrm{m}^{2}\right)$ \\
\hline Çözgü sıklı̆̆ & $30 \mathrm{tel} / \mathrm{cm}$ \\
\hline Atkı sıklığı & $17,5 \mathrm{tel} / \mathrm{cm}$ \\
\hline $\begin{array}{l}\text { Çözgü numarası } \\
(\mathrm{Ne}) \mathrm{N}(\mathrm{Ne})\end{array}$ & 8,1 Ring Karde Şantuk \\
\hline Atkı numarası $(\mathrm{Ne})$ & $\begin{array}{l}10 \mathrm{Ring} \text { Karde }+78 \mathrm{dtex} \\
\text { Elastan }\end{array}$ \\
\hline En & $153 \mathrm{~cm}$ \\
\hline Tarak & $60 / 4$ \\
\hline Boyama Türü & Slasher Boyama \\
\hline
\end{tabular}

Çalışmada kullanılan numune kumaş, slasher boyama ünitesinde boyanıp haşıllanmaktadır. Sırasıyla boyama esnasında uygulanan proses adımları Çizelge 2'de gösterilmiştir. Boyama sülfür bottom tekniği uygulanarak yapılmıştır. Bu teknikte kumaşa indigo boyamadan önce ilk adımda tek teknede sülfür boyama yapılmaktadır. Yapılan sülfür boyama sonrası, çözgülerin (ipliğin) üzerinde bulunan uçuntuları ve pislikleri temizlemek, fazla kimyasallardan arındırmak 
amacıyla 3 tekneli ön yıkama yapılmıştır. Yıkamadan sonra kurutma silindirlerinden geçen çözgü iplikleri, boyanmak üzere içinde indigo boya bulunan teknelere girerek indigo boyama işlemi gerçekleşmiştir.

Çizelge 2. Boyamada uygulanan proses adımları

\begin{tabular}{|c|l|}
\hline Adım & Proses \\
\hline 1 & Sülfür boyama \\
\hline 2 & Ön yıkama \\
\hline 3 & İndigo boyama \\
\hline 4 & Son yıkama \\
\hline 5 & Haş1l \\
\hline
\end{tabular}

Bu adımla birlikte renkte derinlik sağlanmaktadır. $\mathrm{Bu}$ sayede elde edilen renk, koyu ve sarı nüanslı olmaktadır. Bundan sonraki adımda boyamadan çıkan çözgüler son yıkama teknelerine girerek üzerindeki fazla boyadan arındırılmaktadır. Son adımda ise çözgülerin haşı işlemi gerçekleşmektedir. Numune kumaşa uygulanan kimyasal ve fiziksel bitim işlemleri adımları Çizelge 3'de gösterilmiştir.

Çizelge 3. Uygulanan bitim proses adımları

\begin{tabular}{|c|l|}
\hline Adım & Proses \\
\hline 1 & Yakma \\
\hline 2 & Merserize \\
\hline 3 & Y1kama \\
\hline 4 & Apre \\
\hline 5 & Sanfor \\
\hline
\end{tabular}

Kumaşın öncelikle üzerinde bulunan hav ve tüycüklerin yok edilmesi için çift yüz yakma işleminden geçirilmiştir. Daha sonra kumaş yüzeyinde parlaklık elde etmek ve kumaşa ekstra mukavemet kazandirmak amaciyla NAOH (sodyumhidroksit ) verilerek merserizasyon ișlemi yapılmıştır. Sonrasında kumaş üzerindeki kimyasalları uzaklaştırmak için yıkama işlemi uygulanmıştır. Temizlenen kumaş; yumuşaklık ve dolgunluk verilmesi amaciyla yumuşatma apresinden geçirilmiştir. Son aşamada ise kumaşa çekmezlik vermek amacıyla sanfor işlemi uygulanmıştır.

\subsection{Metot}

Fiziksel test laboratuvarında yapılan bu kontroller test esaslı olup, kumaşın fiziksel özelliklerinin kontrolünü sağlar. Yapılan çalışmada yıkamaların kumaş üzerinde etkisini görmek amaciyla uygulanacak testler ve metotlar Çizelge 4'de verilmiştir. Ayrıca testlerin her birine verilen kısaltmalar da Çizelge 4'de yer almaktadır. Yapılan test sonuç çizelgelerinde ve istatistik analizlerde bu kısaltmalar kullanılmıştır. Uygulanan testler bu alanda en çok kullanılan ASTM D, ISO, LS \& CO gibi uluslararas1 standartlara uygun olarak yapılmıştır.

Çizelge 4. Denim kumaşlara uygulanan test metotlar1 ve k1saltmalar [8-14]

\begin{tabular}{|c|c|c|c|}
\hline Kisalt. & Test Adı & Birim & $\begin{array}{c}\text { Test } \\
\text { Metodu }\end{array}$ \\
\hline G & $\begin{array}{c}\text { Kumaş gramajı } \\
{[8]}\end{array}$ & $\mathrm{g} / \mathrm{m}^{2}$ & $\begin{array}{c}\text { ASTM D } \\
3776 \\
\end{array}$ \\
\hline EN & En kontrolü [9] & $\mathrm{cm}$ & $\begin{array}{c}\text { ASTM D } \\
3774\end{array}$ \\
\hline S & Katılık [10] & $\mathrm{kg}$ & $\begin{array}{c}\text { ASTM D } \\
4032\end{array}$ \\
\hline WE & $\begin{array}{c}\text { Çözgü uzaması } \\
{[11]}\end{array}$ & $\%$ & $\begin{array}{l}\text { ASTM D } \\
3107\end{array}$ \\
\hline M & Dönme [12] & $\%$ & $\begin{array}{c}\text { LS\&CO } \\
\text { Method } 2\end{array}$ \\
\hline AK & $\begin{array}{c}\text { Atkı kopma } \\
\text { mukavemeti [13] }\end{array}$ & $\mathrm{kg}$ & $\begin{array}{l}\text { ASTM D } \\
5034\end{array}$ \\
\hline ÇK & $\begin{array}{l}\text { Çözgü kopma } \\
\text { mukavemeti [13] }\end{array}$ & $\mathrm{kg}$ & $\begin{array}{l}\text { ASTM D } \\
5034\end{array}$ \\
\hline ÇÇ & $\begin{array}{c}\text { Çözgü çekme } \\
{[14]}\end{array}$ & $\%$ & $\begin{array}{c}\text { TS EN ISO } \\
5077\end{array}$ \\
\hline $\mathrm{AÇ}$ & Atk1 çekme [14] & $\%$ & $\begin{array}{c}\text { TS EN ISO } \\
5077\end{array}$ \\
\hline
\end{tabular}

Yapılan denemeler ve rins işlem adımları Çizelge 5'de yer almaktadır. Bu yıkama türünün kısa bir işlem olması nedeniyle uygulanan işlemler 4 adımdan oluşmaktadır. İlk adımda yıkama işlemi yapılmakta, sonrasında ise boşaltma, sıkma ve kurutma işlemi uygulanarak işlem sona ermektedir. 
Çizelge 5. Rins yıkama reçetesi

\begin{tabular}{|c|c|c|c|c|}
\hline İşlem & $\begin{array}{l}\text { Flotte } \\
\text { oranı } \\
(\mathrm{kg} / \mathrm{l})\end{array}$ & $\begin{array}{c}\text { Sicaklık } \\
\left({ }^{\circ} \mathrm{C}\right)\end{array}$ & Süre (dk) & pH \\
\hline $\begin{array}{c}\text { Rinse } \\
\text { Y1kama }\end{array}$ & $1 / 14$ & $\begin{array}{l}\text { D1*: } 25 \\
\text { D2*: } 45 \\
\text { D3*: } 65\end{array}$ & $\begin{array}{l}\text { D1*: } 5 \\
\text { D2*: } 15 \\
\text { D3*: } 30\end{array}$ & $6-7$ \\
\hline \multicolumn{5}{|c|}{ Boşaltma } \\
\hline \multicolumn{5}{|c|}{ S1kma } \\
\hline \multicolumn{5}{|c|}{ Kurutma } \\
\hline
\end{tabular}

$\mathrm{D}^{*}$ Deneme

Çizelge 6. Rins yıkama denemelerinde kullanılan parametreler

\begin{tabular}{|c|c|}
\hline Sicaklık $\left({ }^{\mathbf{0}} \mathbf{C}\right)$ & Süre (dk) \\
\hline 25 & 5 \\
\hline 25 & 15 \\
\hline 25 & 30 \\
\hline 45 & 5 \\
\hline 45 & 15 \\
\hline 45 & 30 \\
\hline 65 & 5 \\
\hline 65 & 15 \\
\hline 65 & 30 \\
\hline
\end{tabular}

Çalışmalarda yapılan analizler için rins yıkamada süre ve sıcaklık parametreleri üzerinde değişikler yapılarak fiziksel testler uygulanmıştır. Yıkamalar $5 \mathrm{dk}, 15 \mathrm{dk}$ ve $30 \mathrm{dk}$ sürelerinde yapılmış olup, eş zamanlı olarak sicaklıklar $25^{\circ} \mathrm{C}, 45^{\circ} \mathrm{C}$ ve $65^{\circ} \mathrm{C}$ olarak uygulanmıştır. Denemelerde kullanılan parametreler Çizelge 6'da verilmiştir.

\section{BULGULAR VE TARTIŞMA}

Yapılan rins yıkama denemeleri sonrasında, kumaşlara en, gramaj, çözgü, çekme, atkı çekme, dönme, çözgü uzama, katılık, çözgü kopma, atk1 kopma testleri uygulanmıştır. Çalışmada testler hassasiyeti artırmak amaciyla 3 tekrarlı olarak uygulanmıştır. Sonuçlar deneylerin sütunları üzerinde gruplandırılmıştır. Elde edilen sonuçlar neticesinde veriler SPSS 21 istatistiksel analiz programı yardımıyla değerlendirilmiştir. Test sonuçlarının normal dağılıma uygunluğunu tespit etmek için uygulanan Kolmogrov Smirnov test sonuçları Çizelge 7'de gösterilmiştir. Kolmogrov Smirnov normallik testinin sonuçlarına göre $\mathrm{P}$ önemlilik değerinin 0,05 'ten yüksek olmas1 durumunda verilerin normal dağılıma uygun olduğu kabul edilir.

Çizelge 7. Normal dağılıma uygunluk sonuçları

\begin{tabular}{|c|c|c|c|c|c|c|c|c|c|}
\hline & GR & $\mathbf{E N}$ & $\mathbf{C C C}$ & $\mathbf{A C ̧}$ & $\mathbf{M}$ & $\mathbf{W E}$ & $\mathbf{S}$ & $\mathbf{C \zeta K}$ & $\mathbf{A K}$ \\
\hline $\mathbf{N}$ & 27 & 27 & 27 & 27 & 27 & 27 & 27 & 27 & 27 \\
\hline $\mathbf{P}$ & 0,2 & 0,2 & 0,2 & 0,05 & 0,2 & 0,0 & 0,03 & 0,2 & 0,2 \\
\hline
\end{tabular}

Çizelge 7 incelendiğinde özellikle katılık ve çözgü uzama testlerinde önemlilik değerinin 0,05 'den küçük olduğu ve normal dağılıma uygun olmadığ1 görülebilmektedir. Diğer değerlerin ise 0,05 'den büyük ve normal dağılıma uygun olduğu görülmektedir. İlgili parametrelerin histogram grafikleri incelendiğinde (Şekil 1) çözgü uzama ve stifness test sonuçlarının çan şekline oldukça yakın, tek tepe noktasına ve geniş bir dağılma aralığına sahip olduğu görülebilmektedir. Merkezi limit teoremi, normal olmayan dağılımların normale yakın kabul edilmesini sağlamakta, dolayısıyla Şekil 1'deki faktörlerin de normal dağılım gösterdiği kabul edilmektedir [15].

Çizelge 8'deki hata varyanslarının eşitliği test sonuçlarına bakıldığında atkı kopma değerlerinin varyanslarının homojen dağılım göstermediği yani $\mathrm{P}$ değerinin 0,05 'ten küçük olduğu, diğer değerlerin varyanslarının ise homojen dağılım gösterdiği anlaşılmaktadır ( $p>0,05)$. Atkı kopma mukavemeti varyansları homojen dağılmadığından Tamhane çok değişkenli varyans analizi testleri uygulanmıştır (Çizelge 19). Diğer değişkenler homojen dağılım gösterdiğinden Tukey HSD testi yapılarak sonuçlar değerlendirilmiştir (Çizelge 11,13,15,17).

$\mathrm{Bu}$ analizlerde, süre faktörü için 5, 15 ve $30 \mathrm{dk}$ 'da elde edilen sonuçlar, sıcaklık faktörü için ise 25,45 ve $65^{\circ} \mathrm{C}$ ortalamaları arasındaki farklardan yola çıkarak ikili olarak mukayeseler yapılmıştır. 

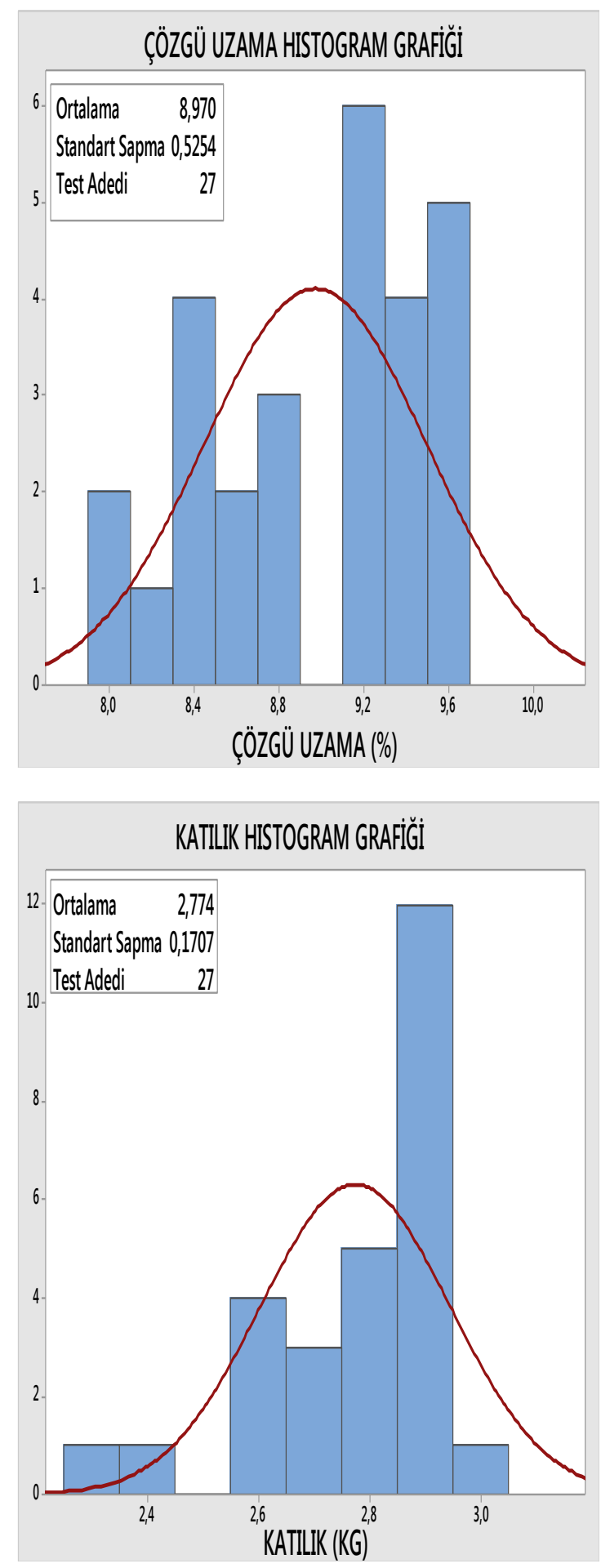

Şekil 1. Katılık ve çözgü uzama histogram
Çizelge 8. Hata varyanslarının eşitliği sonuçları levene's test of equality of error variances $^{\mathrm{a}}$

\begin{tabular}{|l|c|c|c|c|}
\hline & F & df1 & df2 & P \\
\hline GR & 1,411 & 8 & 18 & 0,258 \\
EN & 1,284 & 8 & 18 & 0,312 \\
ÇÇ & 0,872 & 8 & 18 & 0,557 \\
AÇ & 1,988 & 8 & 18 & 0,108 \\
M & 1,23 & 8 & 18 & 0,337 \\
WE & 1,298 & 8 & 18 & 0,305 \\
S & 1,689 & 8 & 18 & 0,169 \\
ÇK & 1,477 & 8 & 18 & 0,233 \\
AK & 3,058 & 8 & 18 & 0,023 \\
\hline
\end{tabular}

\subsection{Kumaş Gramaj, En, Atkı Çekmesi ve Çözgü Çekmesi Sonuçlarının Değerlendirilmesi}

Aralarındaki ilişkiden dolayı, rins yıkama sonrası elde edilen gramaj, en, çözgü çekmesi ve atk1 çekmesi testlerinin ortalama sonuç grafikleri, Şekil 2,3,4 ve 5'de toplu olarak verilmiştir. Sonuçlara bakıldığında, sıcaklık faktörünün, gramaj, en, çözgü çekmesi ve atk1 çekmesi test sonuçları üzerinde anlamlı bir etkisinin olmadığ görülmektedir. İstatistiksel olarak bakıldığında da Çizelge 9'da yer alan etkileşim sonuçlarında önemlilik değeri 0,05 'den büyük olması nedeniyle sıcaklık ve sıcaklık*süre etkileşiminin etkili olmadığ 1 teyit edilmektedir. Süre sonuçlarının etkisine bakıldığında ise, hem grafikteki eğilimden hem de etkileşim analizi sonuçlarında, önemlilik değerlerini incelediğimiz dört bağımlı değişken için de değerin 0,05 'den küçük olması nedeniyle, süre faktörünün bu değiş̧kenler üzerinde anlamlı ve etkili olduğu sonucuna varmaktayı. Yıkamayla birlikte ipliklerin birbirlerine yaklaşmaları sonucu çözgü ve atkı ipliklerinin sıklıklarında artış olması beklenir. $\mathrm{Bu}$ nedenle sürenin uzamasıyla belirli miktarda sıklık artışına bağlı olarak yıkama sonrası birim alana düşen ağırlıklarda artış gerçekleşmiştir. Gramaj değerleri sürenin kısa olması nedeniyle 5 dk'da düşük değerlerde seyrederken, süre 15 dk'ya uzadıkça gramaj yükselmekte, fakat $30 \mathrm{dk}$ 'da artışın çok fazla olmadığı, 15 dk'ya yakın sonuçların elde edildiği görülmektedir (Şekil 2). 


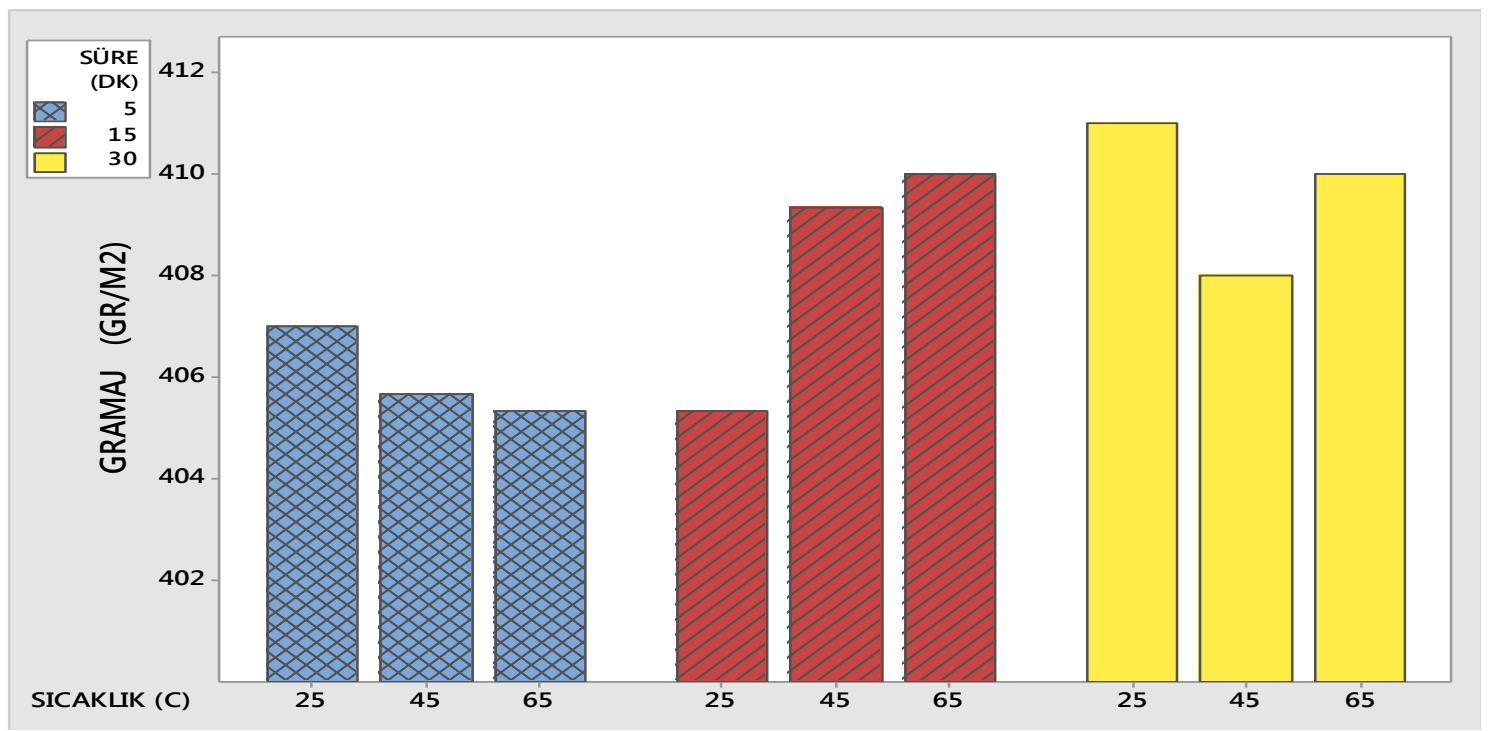

Şekil 2. Rins yıkama sonrası gramaj test sonuçları

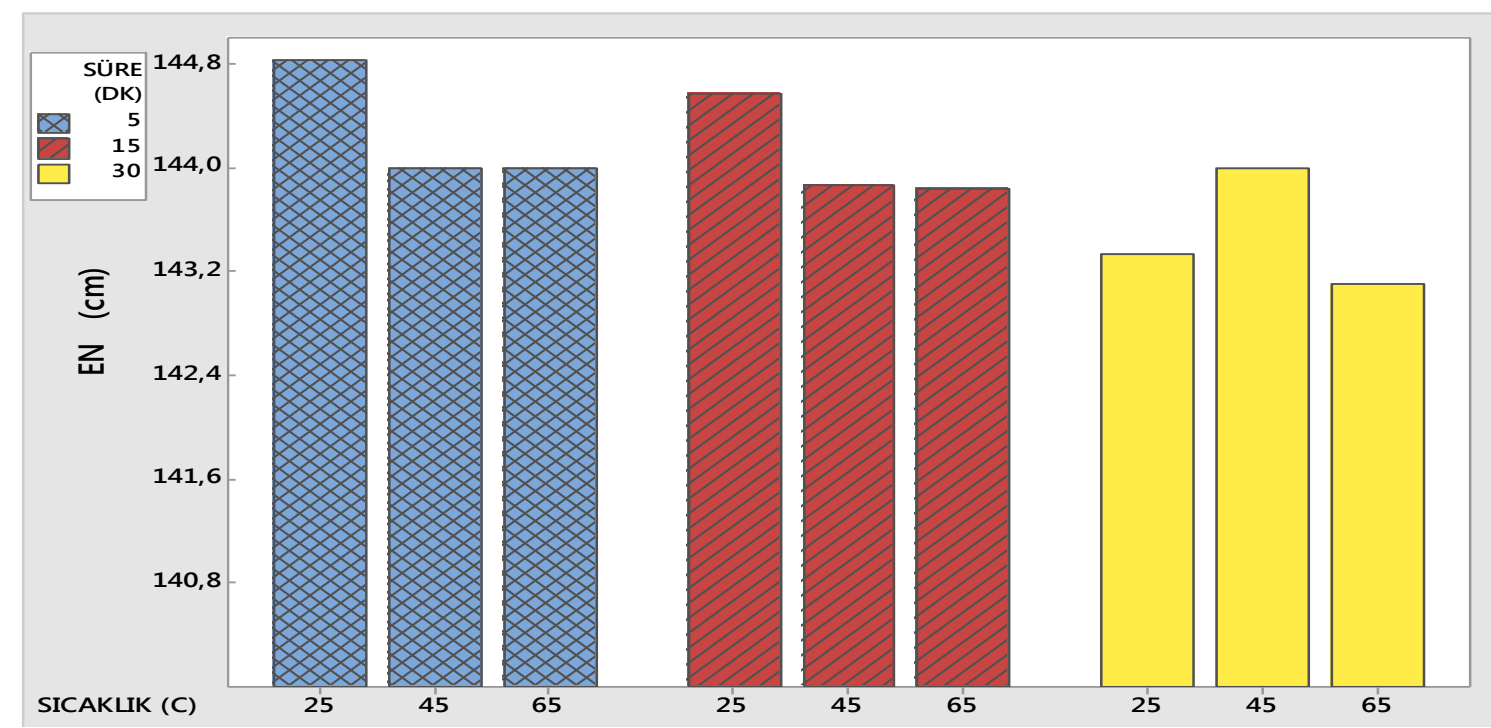

Şekil 3. Rins yıkama sonrası en testi sonuçları

Kumaş en değerlerinin yıkama süresinin uzamasının etkisiyle bir miktar daraldığı görülmektedir. Atk1 yönünde elastan iplikle üretilmiş olan kumaşın yıkamanın etkisiyle birlikte ipliklerin bir araya toplanarak ende daralmaya yol açtığı görülmektedir. Bu nedenle kumaş eninde daralmanın olması beklenen bir durumdur. Özellikle $5 \mathrm{dk}$ sonra ve $15 \mathrm{dk}$ sonrası en değerlerinin birbirine daha yakın çıktığı, süre uzadıkça 30 dk'da elde edilen sonuçlarla en düşük değerlere ulaşıldığı görülmektedir. Sıcaklık sonuçlarında ise 5 ve $15 \mathrm{dk}$ sürelerinde yapılan yıkamalarda, 45 ve $65^{\circ} \mathrm{C}$ sicakliklarda, enlerde daralma görülürken, $30 \mathrm{dk}$ 'da ise sıcaklığa bağlı anlamlı bir değişim görülmemektedir. Bu nedenle test sonuçlarına göre, sicaklığın en üzerinde etkisinin süreye göre daha az olduğu görülmektedir (Şekil3). 


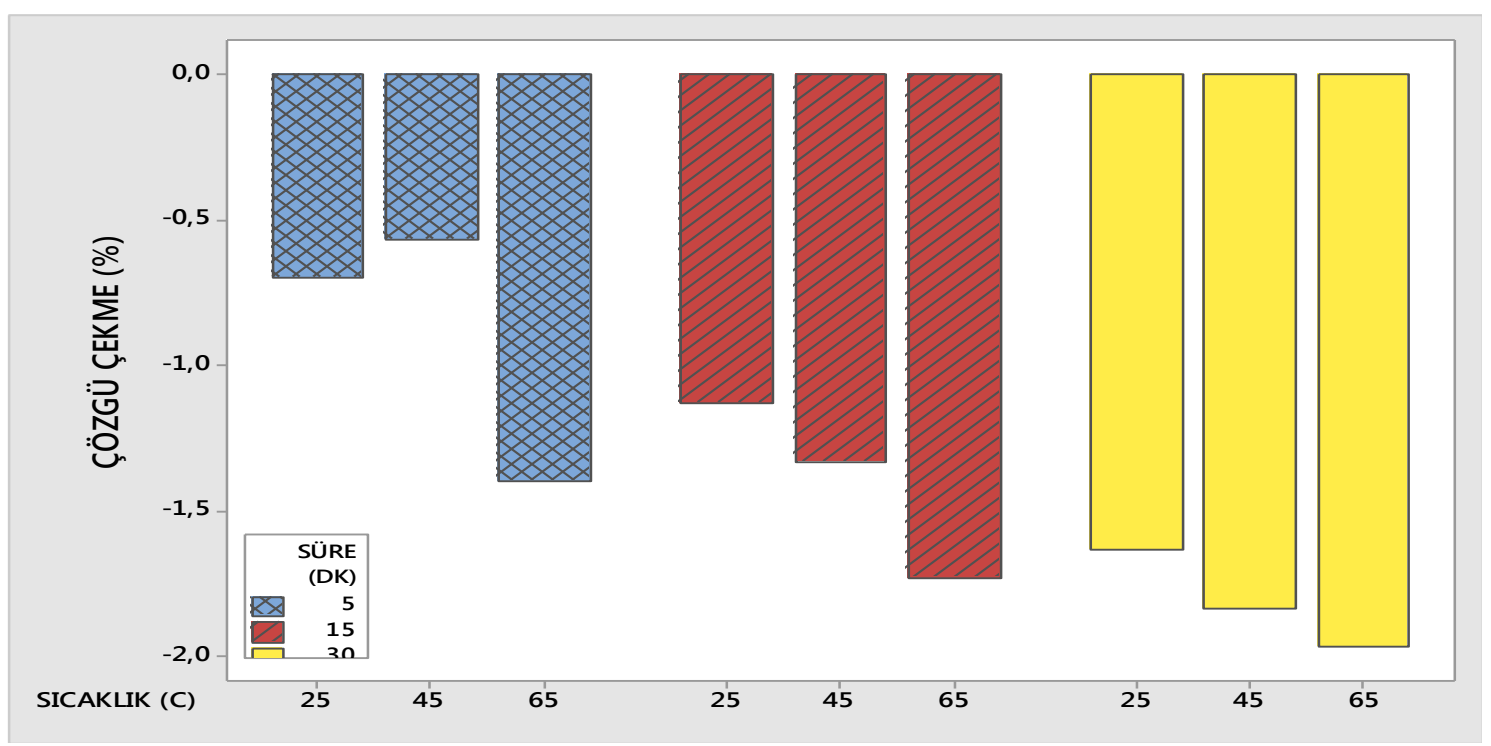

Şekil 4. Rins yıkama sonrası çözgü çekme test sonuçları

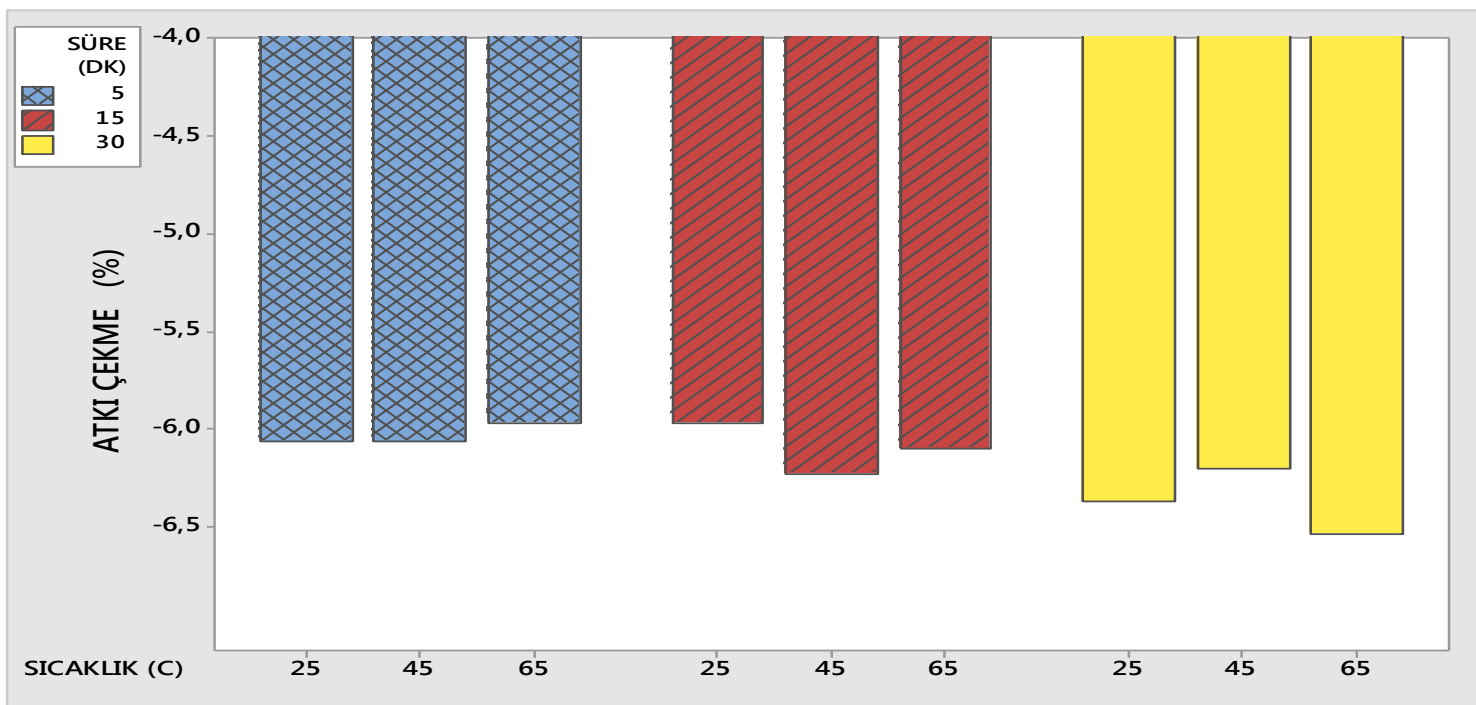

Şekil 5. Rins yıkama sonrası atkı çekme test sonuçları

Kumaşlar yıkanarak kumaş bünyesinde bulunan liflerin şişmesiyle birlikte, iç gerilimlerden kurtulurlar. Böylece boydan daralma gerçekleşir. Çözgü çekmesi için Şekil 3'e baktığımızda, $5 \mathrm{dk}$ değerleri \%0,5-1,5 aralığında ve en az çekme miktarına sahip iken, 30 dk'daki değerlere baktığımızda \%1,5-2 aralığında değiştiği görülmektedir. Sicaklık değerlerinin ise süre $5 \mathrm{dk}$ 'da iken çok fazla etkili olmadığ 1 görülürken,
15 ve 30 dk'larda sicaklığın artmasıyla birlikte kumaştaki daralmanın da kademeli olarak arttığ1 görülmektedir. Şekil 4'de yer alan atkı çekmesi test sonuçlarını irdelediğimizde süre parametresinin artmasıyla birlikte yine hafif de olsa bir değişim göze çarpmaktadır. Özellikle 5 ve $15 \mathrm{dk}$ değerleri birbirine yakın olmasıyla birlikte 30 dk'daki atkı çekme test sonuçlarının bunlardan daha yüksek olduğunu görülmektedir. 
Çizelge 9. Süre ve sıcaklık faktörlerinin gramaj, en, çözgü çekmesi ve atkı çekmesine etkisi

\begin{tabular}{|c|c|c|c|}
\hline & Faktör & $\mathbf{F}$ & Önemlilik \\
\hline \multirow{3}{*}{ GR } & Süre & 4,433 & 0,027 \\
\hline & Sicaklık & 0,23 & 0,797 \\
\hline & $\begin{array}{l}\text { Süre * } \\
\text { Sicaklık }\end{array}$ & 1,939 & 0,148 \\
\hline \multirow{3}{*}{ EN } & Süre & 5,413 & 0,014 \\
\hline & Sicaklık & 2,787 & 0,088 \\
\hline & $\begin{array}{l}\text { Süre * } \\
\text { Sicaklık }\end{array}$ & 1,811 & 0,171 \\
\hline \multirow{3}{*}{ ÇÇ } & Süre & 6,591 & 0,007 \\
\hline & Sicaklık & 2,634 & 0,099 \\
\hline & $\begin{array}{l}\text { Süre * } \\
\text { Sicaklık }\end{array}$ & 0,339 & 0,848 \\
\hline \multirow{3}{*}{$\mathrm{AÇ}$} & Süre & 8,308 & 0,003 \\
\hline & Sicaklık & 0,297 & 0,747 \\
\hline & $\begin{array}{l}\text { Süre * } \\
\text { S1caklık }\end{array}$ & 2,027 & 0,133 \\
\hline
\end{tabular}

Yıkama süresi arttıkça atkı yönünde daha önce ende bir daralma olduğunu görmüştük. Buna bağlı olarak beklendiği gibi atkı çekme oranında da bir artış olduğu göze çarpmaktadır. Elde edilen sonuçlar ikili olarak kıyaslandığında, rins yıkama sonrası gramaj için 5 ve $30 \mathrm{dk}$ arasındaki farkın yüksek olduğu ve yıkama süresinin kumaşın daralmasından dolayı birim alana düşen iplik sayısının da artmasıyla gramajda yükselmeye yol açtığ1 buradan da görülmektedir. En, çözgü çekmesi ve atkı çekmesi değerleri için de yine benzer durum tespit edilmiştir. Yıkama süresinin uzamasıyla birlikte özellikle 5 ve $30 \mathrm{dk}$ arasındaki ortalama farkın fazla olması kumaşın boydan ve enden daralmasının süreye bağlı olarak artma eğiliminde olduğunu göstermektedir. Bütün bu ilişkileri toparlayacak olursak, yıkama sonrası en ve boydaki daralmayla beraber atkı ve çözgü çekmesindeki artışla birlikte gramaj değerlerinde de artış görüldüğü sonucuna varılmaktadır.

\subsection{Dönme (Skew Movement) Test Sonuçlarının Değerlendirilmesi}

Rins yıkama sonrası elde edilen kumaş dönme ortalama sonuçları Şekil 6'da yer almaktadır. Bu sonuçlara göre sicaklık parametresiyle dönme değerleri arasında çok fazla etkileşim olmadığı görülmektedir. Süre parametresine göre ise yıkamanın uzamasıyla birlikte dönme değerinin bir miktar azaldığı görülmektedir. Dönme değeri atkının hareketine bağlı olduğundan yıkama süresinin artmasıyla birlikte atkı daha az hareket ederek dönme değerindeki değişimin de azalmasına yol açmıştır. Çizelge 10'da yer alan etkileşimlerden de görüldüğü üzere önemlilik değerinin 0,05 'den düşük olması nedeniyle sürenin dönme üzerinde etkili olduğu görülmekte iken, sıcaklık ve sıcaklık-süre etkileşiminde etkili ve anlamlı bir sonuca varılamamaktadır.

Çizelge 10. Süre ve sıcaklık faktörlerinin dönme üzerindeki etkisi

\begin{tabular}{|l|c|c|}
\hline \multicolumn{1}{|c|}{ Faktör } & F & Önemlilik \\
\hline Süre & 4,186 & 0,032 \\
\hline Sicaklık & 0,43 & 0,657 \\
\hline Süre * Sicaklık & 0,627 & 0,649 \\
\hline
\end{tabular}

Çizelge 11. Dönme değişkeni toplu karşılaştırma sonuçları (TUKEY HSD)

\begin{tabular}{|c|c|c|c|c|c|}
\hline Faktör & $\begin{array}{c}\text { Bağımlı } \\
\text { Değiş. }\end{array}$ & $\begin{array}{c}\text { I } \\
\text { (Süre) } \\
\end{array}$ & $\begin{array}{c}\mathbf{J} \\
\text { (Süre) }\end{array}$ & $\begin{array}{c}\text { Fark } \\
(I-J)\end{array}$ & Önem. \\
\hline \multirow{6}{*}{ SÜRE } & \multirow{6}{*}{ M } & \multirow{2}{*}{5} & 15 & 0,389 & 0,329 \\
\hline & & & 30 & $-0,378$ & 0,349 \\
\hline & & \multirow{2}{*}{15} & 5 & $-0,389$ & 0,329 \\
\hline & & & 30 &,$- 767^{*}$ & 0,025 \\
\hline & & \multirow{2}{*}{30} & 5 & 0,378 & 0,349 \\
\hline & & & 15 &, $767^{*}$ & 0,025 \\
\hline
\end{tabular}


Genelde 2/1 ya da 3/1 dimi örgü yapısında olan denim kumaşlarda, yıkama sonrası atkı eğimi değeri ile yıkama öncesi verilen atkı eğimi değeri arasında fark, atkının yapacağı toplam hareketi, yani dönme değerini ifade etmektedir. Çizelge 11'de yer alan dönme bağımlı değişkeninin süreye göre karşılaştırma sonuçlarına göre, 15 ve $30 \mathrm{dk}$ arasındaki farkın anlamlı olduğu, atkının 15 dakika'ya kadar bir miktar hareket ettiğini, fakat 15 . dakikadan 30. dk'ya kadar geçen sürede ise hareketin daha fazla olduğu ve bu hareketin daha etkili olduğu anlaşılmaktadır.

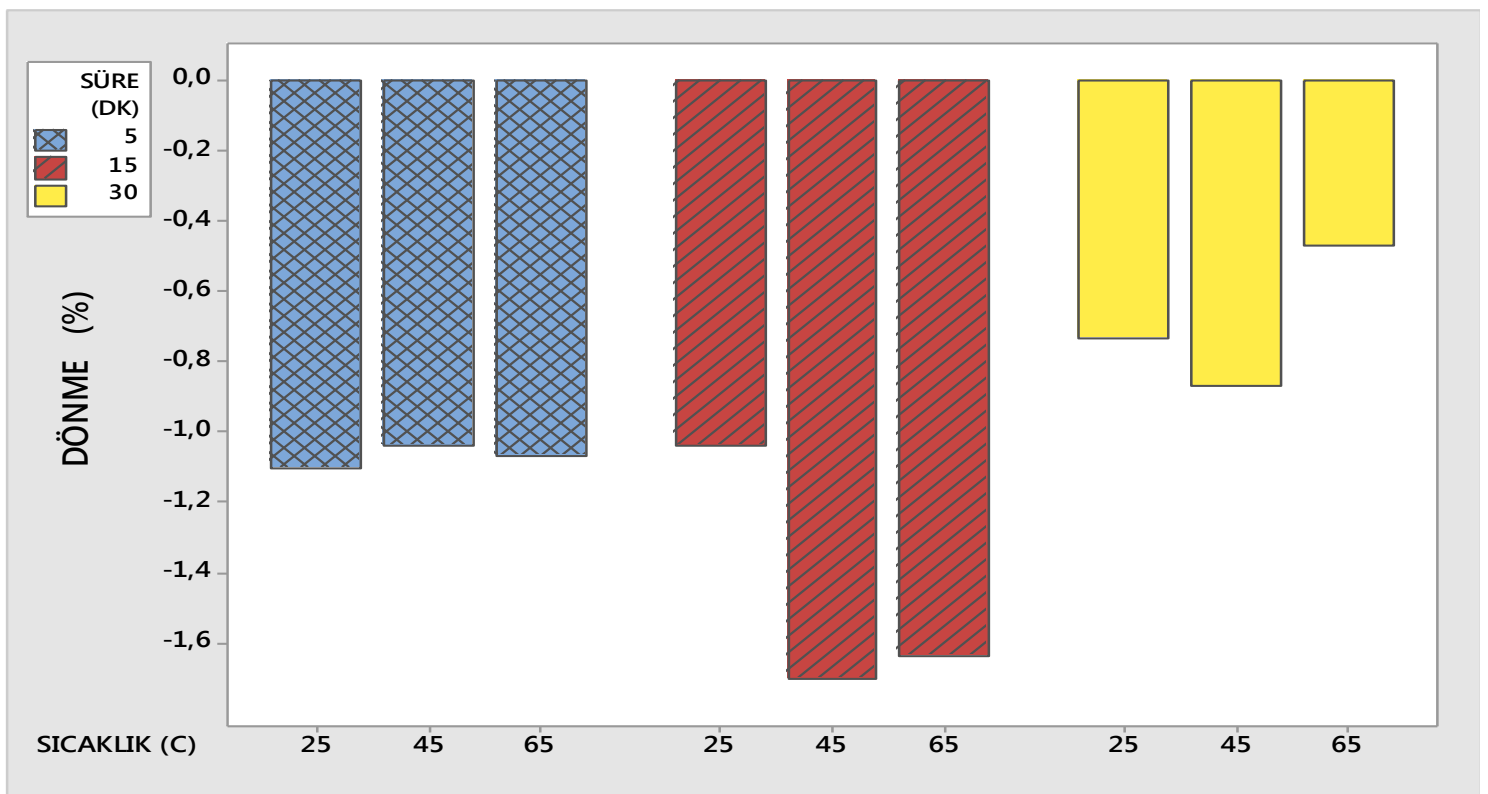

Şekil 6. Rins yıkama sonrası dönme test sonuçları

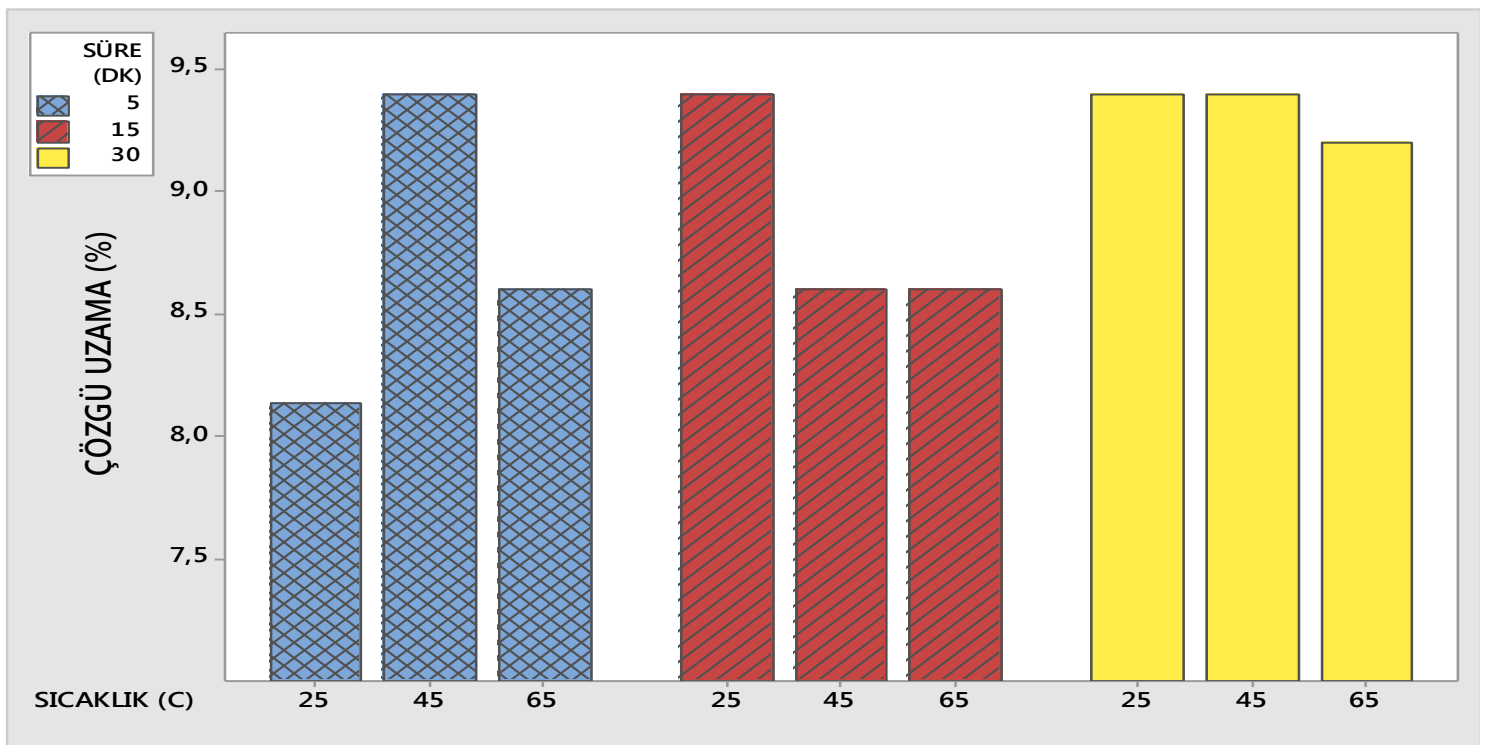

Şekil 7. Rins yıkama sonrası çözgü uzama sonuçları 


\section{3. Çözgü Uzama Test Sonuçlarının Değerlendirilmesi}

Şekil 7'de sıcaklık ve sürelere göre elde edilen çözgü uzaması test sonuçlarının ortalama değerleri görülmektedir. Bu sonuçlara göre sıcaklıkla çözgü uzaması değerleri ilişkilendirilememektedir. Sıcaklık değerinin artışına bağlı olarak çıkan sonuçların aynı doğrultuda ilerlemediği görülmektedir. Çizelge 12'deki önemlilik değerine göre de sıcaklığın çözgü uzaması üzerinde etkili olmadığı görülmektedir. Süreye göre değerlerdeki değişimlere bakıldığında ise etkileşim çizelgesinden de görüldüğü üzere önemlilik değerinin 0,001 olması nedeniyle etkili ve anlamlı bir faktör olduğu, özellikle 30 dakikada değerlerin 5 ve 15 dk'da elde edilen sonuçlara göre çok daha yüksek seyrettiği görülmektedir. Çizelge 13'deki toplu karşılaştırma sonuçlarına bakıldığında da zaten 30 dakika ile 15 ve 5 dakika arasındaki farkın anlamlı olduğu tespit edilmektedir.

Çizelge 12. Süre ve sıcaklık faktörlerinin çözgü uzama üzerindeki etkisi

\begin{tabular}{|l|c|c|}
\hline Faktör & F & Önemlilik \\
\hline Süre & 11,582 & 0,001 \\
\hline Sicaklık & 3,073 & 0,071 \\
\hline Süre * Sicaklık & 10,191 & 0,000 \\
\hline
\end{tabular}

Çizelge 13. Çözgü uzama değişkeni toplu karşılaştırma sonuçları (TUKEY HSD)

\begin{tabular}{|c|c|c|c|c|c|}
\hline Faktör & $\begin{array}{c}\text { Bağımlı } \\
\text { Değiş. }\end{array}$ & I (Süre) & $\underset{\text { (Süre) }}{\mathbf{J}}$ & $\begin{array}{c}\text { Fark } \\
(\mathbf{I}-\mathbf{J})\end{array}$ & Önem. \\
\hline \multirow{6}{*}{ Süre } & \multirow{6}{*}{ WE } & \multirow{2}{*}{5} & 15 & $-0,156$ & 0,494 \\
\hline & & & 30 &,$- 622^{*}$ & 0,001 \\
\hline & & \multirow{2}{*}{15} & 5 & 0,156 & 0,494 \\
\hline & & & 30 &,$- 467^{*}$ & 0,007 \\
\hline & & \multirow{2}{*}{30} & 5 &, $622^{*}$ & 0,001 \\
\hline & & & 15 &, $467^{*}$ & 0,007 \\
\hline
\end{tabular}

Çizelge 13'e göre sürenin uzamasıyla çözgü yönünde daralan kumaşın daha fazla esneme kaydedebildiği sonucuna varılmaktadır. $30 \mathrm{dk}$ 'da en fazla daralma yaşandığı için esnemenin de buna göre fazla çıktığı rahatlıkla söylenebilmektedir.

\subsection{Sertlik Test Sonuçlarının Değerlendirilmesi}

Şekil 8'de sunulan sertlik test sonuçlarına göre sürenin uzamasıyla birlikte sertlik değerinin de arttığı görülmektedir. Özellikle $5 \mathrm{dk}$ 'dan daha uzun sürelerde sonuçlarda yükselme olduğu fakat sonuçların daha yukarı çıkmadığı görülmektedir. Çizelge 14'de yer alan etkileşim sonuçlarında da önemlilik değerinin süre için 0,05 sinır değerinin altında etkili ve anlamlı olduğu, sıcaklık faktörü için ise 0,05 değerinin üzerinde ve etkili olmadığ 1 görülmektedir. Sertlik için kumaşın 5 dk ile 15 ve $30 \mathrm{dk}$ sonuçlarının ortalama farklarının fazla ve anlamlı olduğu, 5 dk'daki değerlerin daha uzun sürelere göre daha düşük olduğu Çizelge 15'de görülmektedir.

Çizelge 14. Süre ve sicaklık faktörlerinin sertlik üzerindeki etkisi

\begin{tabular}{|l|c|c|}
\hline \multicolumn{1}{|c|}{ Faktör } & F & Önemlilik \\
\hline Süre & 17,429 & 0 \\
\hline Sıcaklık & 0,737 & 0,493 \\
\hline Süre * Sicaklık & 0,561 & 0,694 \\
\hline
\end{tabular}

Çizelge 15. Sertlik değişkeni için süre ve sıcaklık faktörleri toplu karşılaştırma sonuçları (TUKEY HSD)

\begin{tabular}{|c|c|c|c|c|c|}
\hline Faktör & $\begin{array}{c}\text { Bağımlı } \\
\text { Değiş. }\end{array}$ & I (Süre) & J (Süre) & $\begin{array}{c}\text { Fark } \\
(\text { I-J) }\end{array}$ & Önem. \\
\hline \multirow{6}{*}{ Süre } & \multirow{6}{*}{$S$} & \multirow{2}{*}{5} & 15 &,$- 2994^{*}$ & 0 \\
\hline & & & 30 &,$- 2522^{*}$ & 0,001 \\
\hline & & \multirow{2}{*}{15} & 5 &, $2994^{*}$ & 0 \\
\hline & & & 30 & 0,047 & 0,668 \\
\hline & & \multirow{2}{*}{30} & 5 &, $2522^{*}$ & 0,001 \\
\hline & & & 15 & $-0,05$ & 0,668 \\
\hline
\end{tabular}




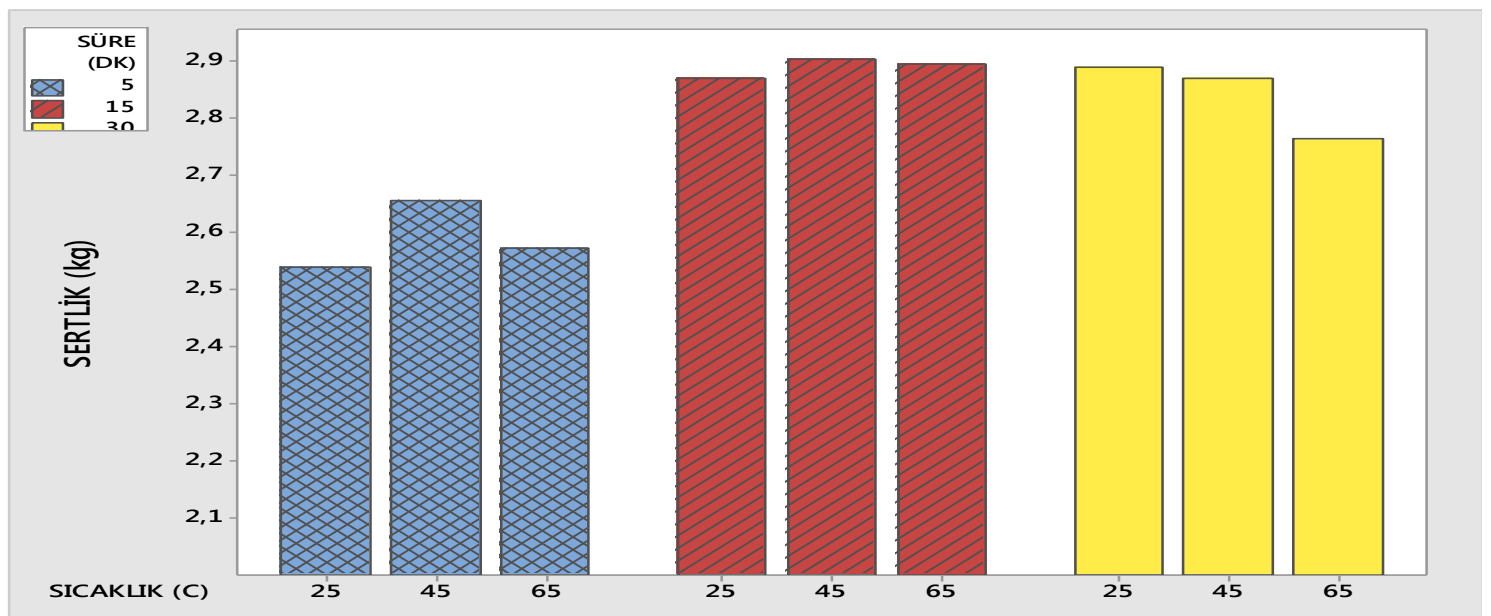

Şekil 8. Rins yıkama sonrası sertlik sonuçları

Ortaya çıkan bu sonuçlar, kumaşa apre aşamasında verilen yumuşatıcının $15 \mathrm{dk}$ 'dan sonra üzerinden atıldığının ve yumuşatma özelliğinin azaldığının göstergesidir. 5 dk'da yumuşatma özelliği tamamen kaybolmamış fakat sürenin uzamasıyla birlikte yumuşatıcı aprenin etkisinin azaldığ görülmüştür. $\mathrm{Bu}$ nedenle sertlik değerinin yıkama süresinin uzamasıyla arttığı ortaya çıkmaktadır.

\section{5. Çözgü Kopması Test Sonuçlarının Değerlendirilmesi}

Şekil 9'da sicaklık ve süre parametrelerine göre yapılan test sonuçlarının ortalama değerleri yer almaktadır. Bu sonuçlara göre süre ile çözgü kopma mukavemeti değerinin çok fazla etkilenmediği, sıcaklığa göre bakıldığında ise, sicaklığın $\quad 30^{\circ} \mathrm{C}$ 'den $\quad 45^{\circ} \mathrm{C}$ 'ye yükseldiğinde mukavemetin düştüğü $60^{\circ} \mathrm{C}^{\prime}$ ye geldiğinde ise tekrar eski değerlerine yakın noktalara geldiği görülmektedir. Etkileşim çizelgesine baktığımızda da (Çizelge 16) önemlilik değerinin süre faktörü için 0,05 değerinden yüksek olduğu, bu nedenle mukavemete etkisinin olmadiğı görülmektedir. Sıcaklık için önemlilik değerinin ise 0,037 bulunması nedeniyle etkili ve anlamlı bir faktör olduğu görülmektedir.

Çizelge 17'deki toplu karşılaştırma sonuçları, $45^{\circ} \mathrm{C}$ ile $65^{\circ} \mathrm{C}$ 'deki çözgü kopması değerleri arasındaki farkın anlamlı bir fark olduğunu göstermektedir. $\mathrm{Bu}$ sonuçlar, sıcaklığın süreden bağımsız olarak $45^{\circ} \mathrm{C}$ 'deki düşüş nedeniyle anlamlı ve etkili bir faktör olduğu, bu nedenle dikkate alınması gerektiğini göstermektedir.

Çizelge 16. Süre ve sıcaklık faktörlerinin çözgü kopma mukavemeti üzerindeki etkisi

\begin{tabular}{|l|c|c|}
\hline \multicolumn{1}{|c|}{ Faktör } & F & Önemlilik \\
\hline Süre & 0,309 & 0,738 \\
\hline Sicaklık & 3,979 & 0,037 \\
\hline Süre * Sicaklık & 0,294 & 0,878 \\
\hline
\end{tabular}

Çizelge 17. Çözgü kopma değişkeni için toplu karşılaştırma sonuçları (TUKEY HSD)

\begin{tabular}{|c|c|c|c|c|c|}
\hline Faktör & $\begin{array}{l}\text { Bağımılı } \\
\text { Değiș. }\end{array}$ & $\begin{array}{c}\text { I } \\
\text { (Sıcak.) }\end{array}$ & $\underset{\text { (Sicak.) }}{\mathbf{J}}$ & $\begin{array}{l}\text { Fark } \\
(\mathbf{I}-\mathbf{J})\end{array}$ & Önem. \\
\hline \multirow{6}{*}{ Sicak. } & \multirow{6}{*}{ ÇK } & \multirow{2}{*}{25} & 45 & 2,689 & 0,175 \\
\hline & & & 65 & $-1,278$ & 0,653 \\
\hline & & \multirow{2}{*}{45} & 25 & $-2,689$ & 0,175 \\
\hline & & & 65 & $-3,967^{*}$ & 0,033 \\
\hline & & \multirow{2}{*}{65} & 25 & 1,278 & 0,653 \\
\hline & & & 45 & $3,967^{*}$ & 0,033 \\
\hline
\end{tabular}




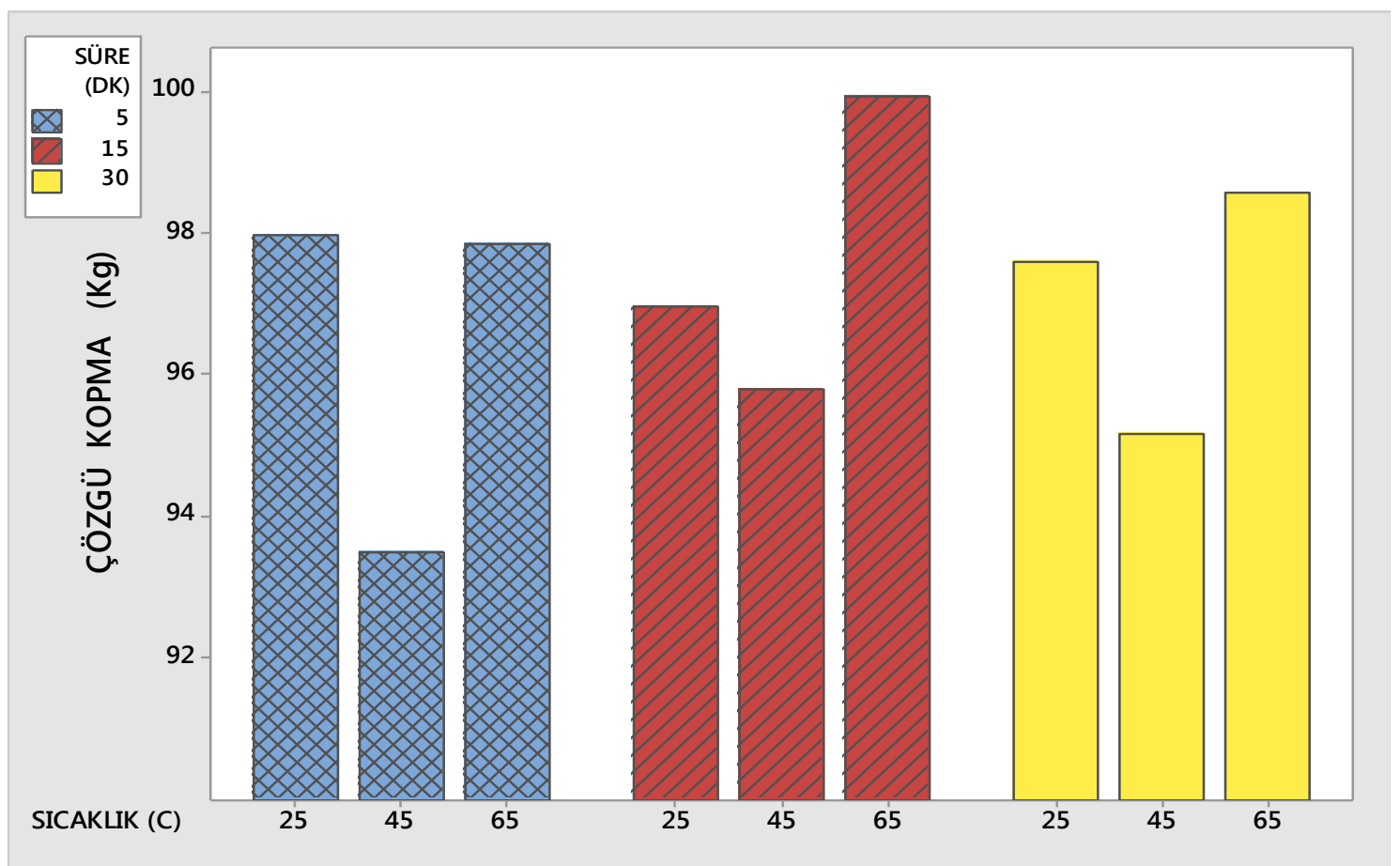

Şekil 9. Rins yıkama sonrası çözgü kopma sonuçları

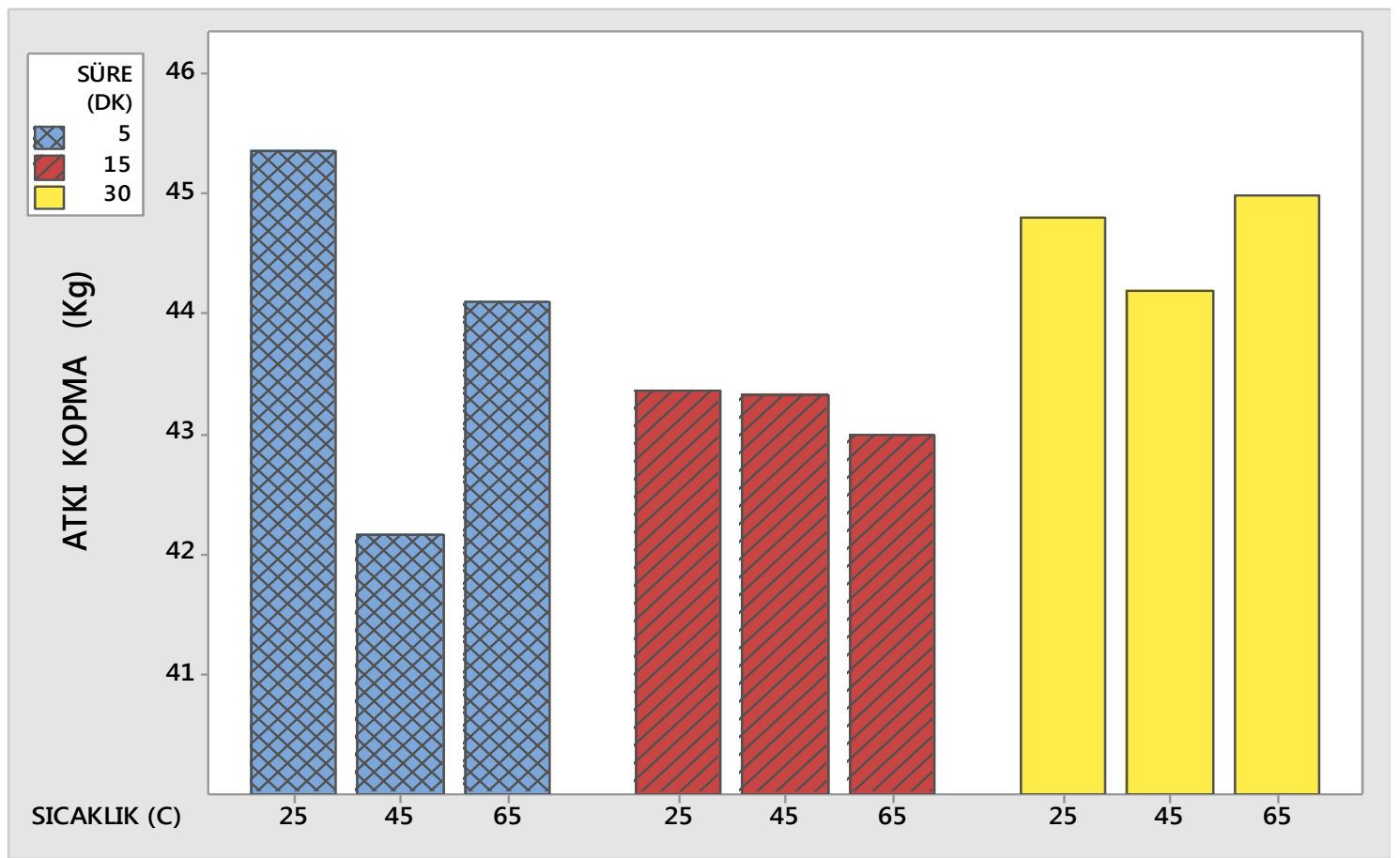

Şekil 10. Rins yıkama sonrası atkı kopma sonuçları 


\subsection{Atkı Kopması Test Sonuçlarının Değerlendirilmesi}

Şekil 10'daki atk1 kopma mukavemet test sonuçlarına bakıldığında süre ve sıcaklıkla atkı kopma mukavemetlerinin hafif bir etkileşim içinde olduğu görülmektedir. Çizelge 18 'daki etkileşim Çizelgesinde de önemlilik değerlerinin 0,05 'den düşük olduğu görülmektedir.

Çizelge 18. Süre ve sıcaklık faktörlerinin atkı kopma üzerindeki etkisi

\begin{tabular}{|l|c|c|}
\hline \multicolumn{1}{|c|}{ Faktör } & F & Önemlilik \\
\hline Süre & 7,916 & 0,003 \\
\hline Sicaklık & 6,403 & 0,008 \\
\hline Süre * Sicaklık & 3,996 & 0,017 \\
\hline
\end{tabular}

İlk 5 dk'daki mukavemet değerinin 15 dk'da düşerek 30 dk'ya geldiğinde tekrar yükselme eğilimine girdiği görülmektedir. Sicaklığa göre bakıldığında da 5 ve $30 \mathrm{dk}$ yıkamalar için $45^{\circ} \mathrm{C}$ ' de mukavemetin düştüğü $65^{\circ} \mathrm{C}$ 'de tekrar yükseldiği görülmektedir.

Çizelge 19. Atkı kopma değişkeni için süre ve sıcaklık faktörleri toplu karşılaştırma sonuçları (TAMHANE)

\begin{tabular}{|c|c|c|c|c|c|}
\hline Faktör & $\begin{array}{l}\text { Bağımlı } \\
\text { Değiş. }\end{array}$ & I (Süre) & J (Süre) & $\begin{array}{c}\text { Fark } \\
(\text { I-J) }\end{array}$ & Önem. \\
\hline \multirow{6}{*}{ Süre } & \multirow{6}{*}{ AK } & \multirow{2}{*}{5} & 15 & 0,644 & 0,613 \\
\hline & & & 30 & $-0,789$ & 0,429 \\
\hline & & \multirow{2}{*}{15} & 5 & $-0,644$ & 0,613 \\
\hline & & & 30 & $-1,433$ & 0,006 \\
\hline & & \multirow{2}{*}{30} & 5 & 0,789 & 0,429 \\
\hline & & & 15 & 1,433 & 0,006 \\
\hline Faktör & $\begin{array}{c}\text { Bağımlı } \\
\text { Değiş. }\end{array}$ & I (Sicak) & J (Sıcak) & $\begin{array}{c}\text { Fark } \\
(\text { I-J) }\end{array}$ & Önem. \\
\hline \multirow{6}{*}{ Sicak. } & \multirow{6}{*}{ AK } & \multirow{2}{*}{25} & 45 & 1,278 & 0,116 \\
\hline & & & 65 & 0,478 & 0,793 \\
\hline & & \multirow{2}{*}{45} & 25 & $-1,278$ & 0,116 \\
\hline & & & 65 & $-0,8$ & 0,214 \\
\hline & & \multirow{2}{*}{65} & 25 & $-0,478$ & 0,793 \\
\hline & & & 45 & 0,8 & 0,214 \\
\hline
\end{tabular}

Cizelge 19'da atk1 kopma değerinde 15 ve $30 \mathrm{dk}$ arasındaki farkın anlamlı olduğu görülmektedir. Sıcaklığa göre anlamlı olarak görülen atkı kopma mukavemeti testinde $45^{\circ} \mathrm{C}$ ile $65^{\circ} \mathrm{C}$ arasında fark göze çarpmaktadır. Mukavemetin $45^{\circ} \mathrm{C}$ 'deki ortalamasının $65^{\circ} \mathrm{C}^{\prime}$ ye göre çok daha düşük olduğu görülmektedir.

\section{SONUÇLAR}

Rins yıkama sonrası elde edilen gramaj sonuçlarında, sürenin artmasına paralel olarak artış yönünde bir eğilim görülmüştür. Rins yıkama sonrası elde edilen en değerlerinin de yıkama süresinin uzamasıyla birlikte daraldığı görülmektedir. Uygulama yapılan kumaş atk1 yönünde elastan bir kumaştır. Yıkamanın etkisiyle birlikte kumaşı oluşturan atkı ve çözgü iplikleri arasındaki mesafenin daralmasıyla birlikte en sonuçlarında da değişim görülmüştür. Gramaj değerleri de bu daralmayla birlikte birim alandaki iplik sayısının artmasına bağlı olarak artış göstermiștir. Sıcaklığın ise, hem kumaş eni hem de kumaş gramajı üzerinde anlamlı bir etkisi bulunamamıştır.

Çekme testlerine bakıldığında hem atkı yönünde hem de çözgü yönünde sürenin artışıyla birlikte çekme miktarlarında da artış gözlenmiştir. Kumaşlar, yıkama sonrası bünyesinde bulunan liflerin şişmesiyle birlikte, iç gerilimlerden kurtulmuş olup, bu sayede kumaşın hem eninde hem de boyunda daralma gerçekleşmiştir. Çözgü çekmesinde ayrıca sıcaklığın da, 15 dakika'dan daha uzun sürelerde, doğrusal bir şekilde çekme sonuçları üzerinde etkili olduğu görülmüştür.

Dönme sonuçlarında süre parametresine göre yıkamanın uzamasıyla birlikte dönme değerinin bir miktar azaldığı görülmektedir. Dönme değeri atkının hareketine bağlı olduğundan yıkama süresinin artmasıyla birlikte atkı daha az hareket ederek dönme değerindeki değişimin de azalmasına yol açtığı düşünülmektedir. Sicaklığın ise dönme üzerinde etkisinin olmadığ görülmüştür. 
Çözgü uzama testinde yıkamada özellikle 30 dakika sürelerine çıkıldığında uzama değerlerinin yükseldiği görülmektedir. $\mathrm{Bu}$ durumdan dolayı, yıkama sonrası elde edilen daralmanın çözgü yönündeki esnemeyi arttırdığı düşünülebilir.

Sertlik sonuçlarında sıcaklığın pek etkili olmadığı görülmektedir. Sürenin 15 dakika ve daha uzun olması durumunda ise birlikte sertlik değerinin arttığı görülmektedir. Bu durumun y1kama süresinin kumaşın üzerinde bulunan yumuşatıc1 etkisini kaybetmesinden kaynaklandığ düşünülmekte, kumaş yıkandıkça sertleşmekte ve sertlik değerleri doğal olarak daha da yükselmektedir.

Mukavemet testlerinde ise rins y1kamanın çok fazla süreyle etkilenmediği görülmektedir. Sicaklıkla etkileşimlerde ise $45^{\circ} \mathrm{C}$ sicaklıkta hem atk1 hem çözgü mukavemetlerinin bir miktar düştüğü tespit edilmiştir.

\section{KAYNAKLAR}

1. Bağıran, İ.C., 2011. Denim Yıkamada Karşılaşılan Sorunlar ve Bunlara Yönelik Çözüm Önerileri, Ege Üniversitesi Fen Bilimleri Enstitüsü Tekstil Mühendisliği, Yüksek Lisans Tezi, İzmir.

2. Dindar, D., Yavuz, B., 2001. 2000-2001 Moda Trendleri ve Kot Pantolon-Mont Üretimi, Marmara Üniversitesi Teknik Eğitim Fakültesi Tekstil Eğitimi Bölümü, Yüksek Lisans Tezi, İstanbul.

3. Card, A., Moore, M.A., Ankeny, M., 2006. Garment Washed Jeans: Impact of Launderings on Physical Properties, International Journal of Clothing Science and Technology, Vol.18, No:2, pp: 43-52.

4. Aslan, M., Körlü, A., 2009. Selülaz Enziminin Denim Yikamada Kullanımı, Tekstil Teknolojileri Elektronik Dergisi, Vol.3, No:1, pp: 11-23.

5. Khedher, F., Dhouib, S., Msahli, S., Saklı, F., 2009. The Influence of Industrial Finishing Treatments and Their Succession on The Mechanical Properties of Denim Garment, Autex Research Journal, Vol.9, No:3. pp: 93100.
6. Yi, C.M., 2011. Effect of Washing on Tensile Strength of Denim Fabric, A Thesis Degree of Bachelor of Arts (Honours) Scheme in Institute of Textiles \& Clothing, The Hong Kong Polytechnic University. Hong Kong.

7. Khan M.R., 2011. Effect of Bleach Wash on The Physical and Mechanical Properties of Denim Garments, International Conference on Mechanical Engineering, pp: 87-93, Dhaka, Bangladesh.

8. ASTM D3776-09a, 2013. Standard Test Methods for Mass Per Unit Area (Weight) of Fabric, ASTM International.

9. ASTM D3774-96, 2016. Standard Test Method for Width of Textile Fabric, ASTM International.

10. ASTM D4032-08, 2016. Standard Test Method for Stiffness of Fabric by the Circular Bend Procedure, ASTM International.

11. ASTM D3107-07, 2015. Standard Test Methods for Stretch Properties of Fabrics Woven from Stretch Yarns, ASTM International.

12. LS\&CO. METHOD-2, 2004. Skew Movement Method in Laundering, Levi's Strauss\&Co.

13. ASTM D5034 - 09, 2013. Standard Test Method for Breaking Strength and Elongation of Textile Fabrics (Grab Test), ASTM International.

14. TS EN ISO 5077, 2012. Tekstil-Yıkama ve Kurutmada Boyut Değişmesinin Tayini, Türk Standartları Enstitüsü, Ankara.

15. Akgül, A., Çevik, O., 2003. İstatistiksel Analiz Teknikleri-SPSS'te İşletme Yönetimi Uygulamaları. Emek Ofset, Ankara. 
